\title{
The activation of IL-17 signaling pathway promotes pyroptosis in pneumonia-induced sepsis
}

\author{
Li-Li Li, Bing Dai, Yu-Han Sun, Ting-Ting Zhang \\ Department of Respiratory and Critical Care Medicine, The First Affiliated Hospital, China Medical University, Shenyang, China \\ Contributions: (I) Conception and design: B Dai; (II) Administrative support: YH Sun; (III) Provision of study materials or patients: LL Li; (IV) \\ Collection and assembly of data: LL Li, TT Zhang; (V) Data analysis and interpretation: LL Li, B Dai; (VI) Manuscript writing: All authors; (VII) \\ Final approval of manuscript: All authors. \\ Correspondence to: Dr. Bing Dai. Department of Respiratory and Critical Care Medicine, the First Affiliated Hospital, China Medical University, No. \\ 155, Nanjing North Street, Shenyang, China. Email: dai6206856@163.com.
}

\begin{abstract}
Background: Pyroptosis is closely relevant to sepsis. However, the molecular mechanisms of pyroptosis in pneumonia-induced sepsis are still not fully understood. Thus, this study aimed to find the specific molecular pathways associated with pyroptosis and explore their relationship in pneumonia-induced sepsis.

Methods: First, significant signaling pathways related to pneumonia-induced sepsis were screened by bioinformatics analysis based on GSE48080. The peripheral blood samples from patients with pneumoniainduced sepsis and healthy subjects were collected. Pneumonia-induced sepsis rat models were also established. Then, inflammatory response, pyroptosis, and regulatory T cells (Tregs)/T-helper 17 (Th17), Th1/Th2, and M1/M2 cell ratios in pneumonia-induced sepsis were evaluated.

Results: IL-17 signaling pathway was significantly related to pneumonia-induced sepsis by bioinformatics analysis. Compared with healthy groups, the higher of Th17/Treg, Th1/Th2 and M1/M2 cell radios in the patients and sepsis rat model indicated that pneumonia-induced sepsis caused a severe inflammatory response. This result was confirmed by higher levels of pro-inflammatory factors (IL-6, TNF- $\alpha$, IL-1 $\beta$, and IL-18) and an inflammation indicator (LDH), as well as pyroptosis occurrence in sepsis. Additionally,

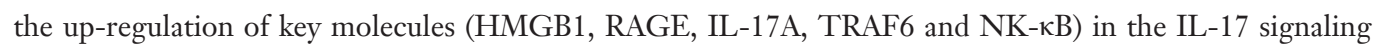
pathway suggested the IL-17 pathway was activated. Moreover, the release of IL-1 $\beta$ and IL-18 and the levels of the molecules (NLRP3, NLRC4, Cleaved caspase-1, and Cleaved GSDMD) associated with caspase-1dependent pyroptosis were up-regulated in pneumonia-induced sepsis.

Conclusions: As NK- $\kappa$ B activation can promote the development of caspase-1-dependent pyroptosis, these findings suggested that the activation of the IL-17 signaling pathway could promote pyroptosis in pneumonia-induced sepsis.
\end{abstract}

Keywords: Pyroptosis; inflammation; T cells subsets; M1/M2 polarization; pneumonia-induced sepsis

Submitted Jul 16, 2019. Accepted for publication May 15, 2020.

doi: $10.21037 /$ atm-19-1739

View this article at: http://dx.doi.org/10.21037/atm-19-1739

\section{Introduction}

Sepsis is a life-threatening infection syndrome complicated by organ dysfunction and systemic inflammation (1). It affects approximately 30 million patients worldwide with high rates of morbidity and mortality as well as great financial cost (2). Sepsis, a response to an infection, can occur in different sits such as urinary tract, digestive system, and respiratory tract (3). Thereinto, the respiratory tract is found to be the focus site of infection in septic patients (4). For instance, community-acquired pneumonia (CAP) remains a major cause of mortality among infectious diseases, because CAP can cause local and systemic inflammation, frequently leading to a dysregulated host 
response and ultimately to severe sepsis or death (5). Despite the increased understanding of pathogenesis and the intensive advances in modern treatment technology such as appropriate antibiotics, aggressive resuscitation and organ support, high mortality rates caused by severe sepsis remain a serious issue $(6,7)$. Therefore, elucidating the underlying mechanism to search for effective therapeutic targets for pneumonia-induced sepsis is quite essential.

Recently, pyroptosis is discovered as a new form of programmed cell death relying on cytosolic inflammasomes activation, accompanied by the release of a large number of pro-inflammatory factors (8). Pyroptosis can be triggered by microbial infections (e.g., Legionella, Francisella or Salmonella) and non-infectious stimuli (e.g., myocardial infarction, cancer, or stroke) (9). Pyroptosis can protect multicellular host organisms against bacterial and microbial infection (10). However, pyroptosis when overactivated becomes detrimental, even leading to sepsis, septic shock, multiple organ dysfunction syndrome (MODS), or increased risk of secondary infection (11). Although several studies have reported the relationship between pyroptosis and sepsis (12), the precise mechanisms underlying pyroptosis in pneumonia-induced sepsis are still not fully understood.

In the present study, significant signaling pathways related to pneumonia-induced sepsis were screened by bioinformatics analysis. Then, inflammatory response and pyroptosis as well as T-helper 17 (Th17)/regulatory T cells (Tregs), Th1/Th2, and M1/M2 cell ratios in pneumoniainduced sepsis were investigated in vivo and in vitro, which was beneficial to understanding the pathogenesis of pneumonia-induced sepsis.

\section{Methods}

\section{Bioinformatics analysis}

The gene expression profile data GSE48080 from patients with sepsis secondary to community-acquired pneumonia (CAP) were obtained from the Gene Expression Omnibus (GEO) repository (http://www.ncbi.nlm.nih.gov/geo/). A total of 13 samples were obtained from this dataset, including 10 mononuclear cells samples from sepsis patients and 3 mononuclear cells samples from healthy controls. The raw downloaded data from GEO were corrected background, normalized and calculated expression using the Bioconductor package (version 3.6) in R language (version 3.4.3). After preprocessing of raw data, the edge $R$ package in $\mathrm{R}$ was utilized to screen differentially expressed genes (DEGs) between sepsis and normal samples. The thresholds were defined as false discovery rate $(\mathrm{FDR})<0.05$ and $\mid \log$ fold change (FC) $\mid>1$ (13). Then based on the top 200 DEGs, Kyoto Encyclopedia of Genes and Genomes (KEGG) pathway enrichment analysis was carried out using ClusterProfiler with the thresholds of $\mathrm{P}$ value less than 0.05 .

\section{Clinical sample collection}

This study obtained ethical approval from the Ethics Committee of The First Affiliated Hospital, China Medical University (Approval Number: AF-SOP-07-1). A total of 20 peripheral blood samples were collected from septic patients secondary to CAP in our hospital between October 2017 and October 2018. In addition, peripheral blood samples from 15 paired healthy subjects were extracted. Written informed consent from all participants was obtained. All patients were adults and enrolled within $48 \mathrm{~h}$ of the first occurrence of organ dysfunction indicative of severe sepsis. The selection indicators: APACHE II scores from 7 to 23 (14) and SOFA scores from 2 to 11 (15). Exclusion criteria were listed as follows: participants under 18 years old; patients with AIDS or end stage chronic illness; patients submitted to immunosuppressive therapy, or any other experimental therapy.

\section{Animal model and grouping}

Approval from the local animal Ethics Committee of the animal laboratory center was obtained prior to experiments. Healthy male Sprague-Dawley (SD) rats (120-150 g) were used for the following experiments after one week of acclimation. Totally, 20 SD rats were randomly and equally assigned to two groups: control group and model group. Pneumonia-derived sepsis rat models were induced with $0.3 \mathrm{~mL}$ Klebsiella pneumoniae $\left(4 \times 10^{10}\right.$ colony forming units/mL, American Type Culture Collection, Manassas, VA, USA) by intravenous injection (14). Rats with control group were treated with $0.3 \mathrm{~mL}$ saline solution. Peripheral blood samples and the lung tissues were obtained for the following experiments.

\section{Enzyme-linked immune-sorbent assays (ELISA)}

Peripheral blood samples from patients and rats were measured by commercial ELISA kits (Boster, Wuhan, China) for the concentrations of interleukins (IL)-17A, IL-1 $\beta$, IL-18, IL-6, and tumor necrosis factor (TNF)- $\alpha$ 
according to the manufacturer's instructions. Briefly, serum samples $(100 \mu \mathrm{L})$ were incubated in a 96-well plate which coated with antigen in each well at $37^{\circ} \mathrm{C}$ for $1.5 \mathrm{~h}$, followed by incubation with biotinylated antibody $(100 \mu \mathrm{L})$ at $37^{\circ} \mathrm{C}$ for $1 \mathrm{~h}$. Afterwards, each well was added with avidine peroxidase $(100 \mu \mathrm{L})$ at $37^{\circ} \mathrm{C}$ for $30 \mathrm{~min}$, substrate solution $(90 \mu \mathrm{L})$ in the dark at $37^{\circ} \mathrm{C}$ for $15 \mathrm{~min}$, and stopping solution $(50 \mu \mathrm{L})$ in turn. Lastly, absorbance at $450 \mathrm{~nm}$ was detected by a microplate reader (Thermo, Philadelphia, PA, USA) to calculate the level of each cytokine.

\section{Isolation of plasma and peripheral blood mononuclear cells (PBMCs)}

Peripheral blood was collected in EDTA-treated tubes, layered on the Ficoll-Paque media solution (FicollHistopaque ${ }^{\circledR}-1077$, Sigma-Aldrich, St. Louis, MO, USA) and centrifuged at $400 \mathrm{~g}$ for $30 \mathrm{~min}$ at $18^{\circ} \mathrm{C}$. Plasma in the upper layer was collected, and the mononuclear cell in the next layer was collected for further analysis.

\section{Lactate debydrogenase (LDH) detection}

Serum LDH was detected to determine cytotoxicity by the commercially available kit (Thermo scientific, Middletown, VA, USA) according to the manufacturer's instructions. Absorbance at $340 \mathrm{~nm}$ was used to calculate LDH level by a microplate reader (Thermo).

\section{Western blotting}

Total proteins from PBMCs were isolated using RIPA Lysis Buffer (Beyotime, Shanghai, China). Then proteins were separated and transferred onto PVDF membranes. After blocked in $5 \%$ skim milk, membranes were probed with primary antibodies against tumor necrosis factor receptorassociated factor (TRAF6), high-mobility group box 1 (HMGB1), receptor for advanced glycation end products (RAGE), nuclear factor (NF)- $\kappa B$, Nod-like receptor pyrin domain containing 3 (NLRP3), NLRC4, Cleavedcaspase1, Cleaved-gasdermin D (GSDMD) (1:1,000, Santa Cruz Biotechnology, Santa Cruz, CA, USA) and GAPDH (1:1,000, Santa Cruz), followed by reacted with secondary antibody (1:10,000, Santa Cruz) and Clarity western ECL substrate (Bio-Rad). The band quantification was performed using Image $\mathrm{J}$ software.

\section{Flow cytometry}

For surface staining, peripheral blood samples were incubated with anti-CD4, anti-CD4, or F4/80 (eBioscience, San Diego, CA, USA) at $4{ }^{\circ} \mathrm{C}$ for $30 \mathrm{~min}$. Then, cells were permeabilized for intracellular staining, which stained with anti-FOXP3, anti-IL-17A, anti-IFN $\gamma$, anti-IL-4, antiinducible nitric oxide synthase (iNOS), and anti-CMAF (Santa Cruz) for Treg, Th17, Th1, Th2, M1 and M2 detections, respectively. Cells were acquired on Canto II flow cytometer (BD Biosciences), and data were analyzed with FlowJo v.9.5.2 software (Tree Star). Lastly, labeled cells were enumerated by Canto II flow cytometer (BD Biosciences, San Jose, CA, USA). Data were analyzed by BD FACSDiva ${ }^{\mathrm{TM}}$ Software 6.0 (BD).

\section{Transmission electron microscopy (TEM)}

Peripheral blood mononuclear cells (PBMCs) were fixed using glutaraldehyde $(3 \%)$ in $\mathrm{PBS}(\mathrm{pH}=7.35)$ at $4{ }^{\circ} \mathrm{C}$ for $2 \mathrm{~h}$, followed by washing with PBS and post-fixation with osmium tetroxide (1\%) for $2 \mathrm{~h}$. After underwent dehydration and embedding, the sections (thickness of 50-60 nm) were cut, and then performed electron-staining (uranyl acetate and lead citrate in turn). Ultimately, the sections were observed under a TEM (HT7700, $80 \mathrm{kV}$, Hitachi, Tokyo, Japan).

\section{Statistical analysis}

GraphPad Prism 6 software was used for data statistical analysis. Data were expressed as the mean \pm SD and analyzed by one-way ANOVA. A value of $\mathrm{P}<0.05$ was considered significant.

\section{Results}

\section{Signaling patbways related to pneumonia-induced sepsis by bioinformatics analysis}

KEGG analysis showed that the top 200 DEGs between sepsis and normal samples were primarily responsible for the top 5 pathways, including IL-17 signaling pathway, transcriptional misregulation in cancer, AGE-RAGE signaling pathway in diabetic complications, malaria, and PID API pathway (Figure 1). IL-17 signaling pathway was selected for the following experiments. 


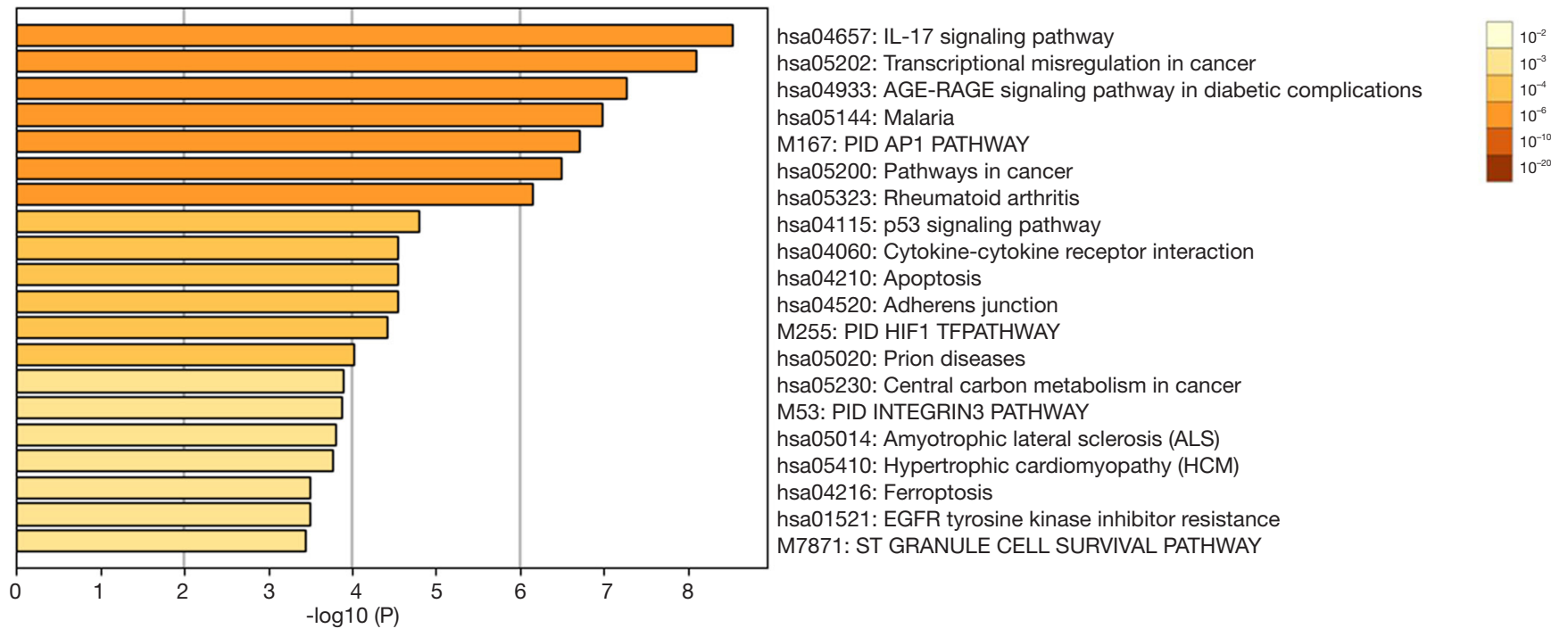

Figure 1 The functional enrichment analyses of the top 200 differentially expressed genes between sepsis and normal samples.

According to the KEGG website, the graph of the IL-17 signaling pathway was listed in Figure S1. In addition, previous literature suggests that the IL-17 family interacts with their correspondent receptors and activates downstream pathways such as NF- $\mathrm{kB}$ to induce the secretion of many pro-inflammatory mediators, including IL-6, TNF- $\alpha$, and IL-1 $\beta$ (16-18). NF- $\kappa$ B activation and high expression of IL- $1 \beta$ are key components of pyroptosis (19). Inspired by these findings, we firstly detected the inflammatory response at the cellular level and then explored the effect of IL-17 signaling pathway on pyroptosis in pneumonia-induced sepsis.

\section{Th17/Treg, Th1/Th2, and M1/M2 cell ratios in patients with pneumonia-induced sepsis}

To identify inflammatory response in patients with pneumonia-induced sepsis at the cellular level, we used to detect the Th17/Treg, Th1/Th2, and M1/M2 cell ratios using flow cytometry. The gating strategy of flow cytometry has been listed in Figures $S 2, S 3$. As shown in Figure $2 A$, the percentages of Treg cells $\left(\mathrm{CD}^{+}, \mathrm{FOXP}^{+}\right)$were obviously lower in patients with pneumonia-induced sepsis than those in the control group $(6.13 \%$ vs. $11.2 \%)$. However, the percentages of Th17 cells $\left(\mathrm{CD} 4^{+}, \mathrm{IL}-17^{+}\right)$were significantly higher than those in the control group (13.4\% vs. 9.69\%).

Figure $2 B$ indicates that the percentages of Th 1 cells $\left(\mathrm{CD}^{+}, \mathrm{IFN} \gamma^{+}\right)$greatly increased in patients with pneumonia-induced sepsis compared with the control group (14.1\% vs. $7.98 \%)$. In contrast, the percentages of Th2 cells $\left(\mathrm{CD}^{+}, \mathrm{IL}-4^{+}\right)$obviously decreased in the patients as compared to the control group (2.05\% vs. $4.43 \%)$.

Additionally, compared with the control group, Figure $2 C$ shows that the percentages of $\mathrm{M} 1$ cells $\left(\mathrm{F} 4 / 80^{+}\right.$, iNOS $\left.{ }^{+}\right)$ were higher in patients with pneumonia-induced sepsis (19.1\% vs. 11.1\%), while the percentages of M2 cells $\left(\mathrm{F} 4 / 80^{+}, \mathrm{Cmaf}^{+}\right)$were lower $(3.85 \%$ vs. $10.7 \%)$.

Collectively, The Th17/Treg, Th1/Th2 and M1/M2 radios were up-regulated in the patients compared with the control group. There was a higher frequency of IL$17, \mathrm{IFN} \gamma$, and iNOS production and a lower frequency of FOXP3, IL-4, and Cmaf production. Hence, the radio imbalance indicated that there was a severe inflammatory response in patients with pneumonia-induced sepsis.

\section{Inflammatory response and pyroptosis in patients with pneumonia-induced sepsis}

To explore the effect of IL-17 signaling pathway on pyroptosis in patients with pneumonia-induced sepsis, we detected the changes of upstream and downstream molecules (HMGB1, RAGE, IL-17A, TRAF6 and $\mathrm{NK}-\kappa \mathrm{B})$ in the IL-17 signaling pathway. The other proinflammatory factors (IL-6, TNF- $\alpha$, IL-1 $\beta$, IL-18) and an inflammation indicator ( $\mathrm{LDH}$, Lactate dehydrogenase) were also measured. 
A

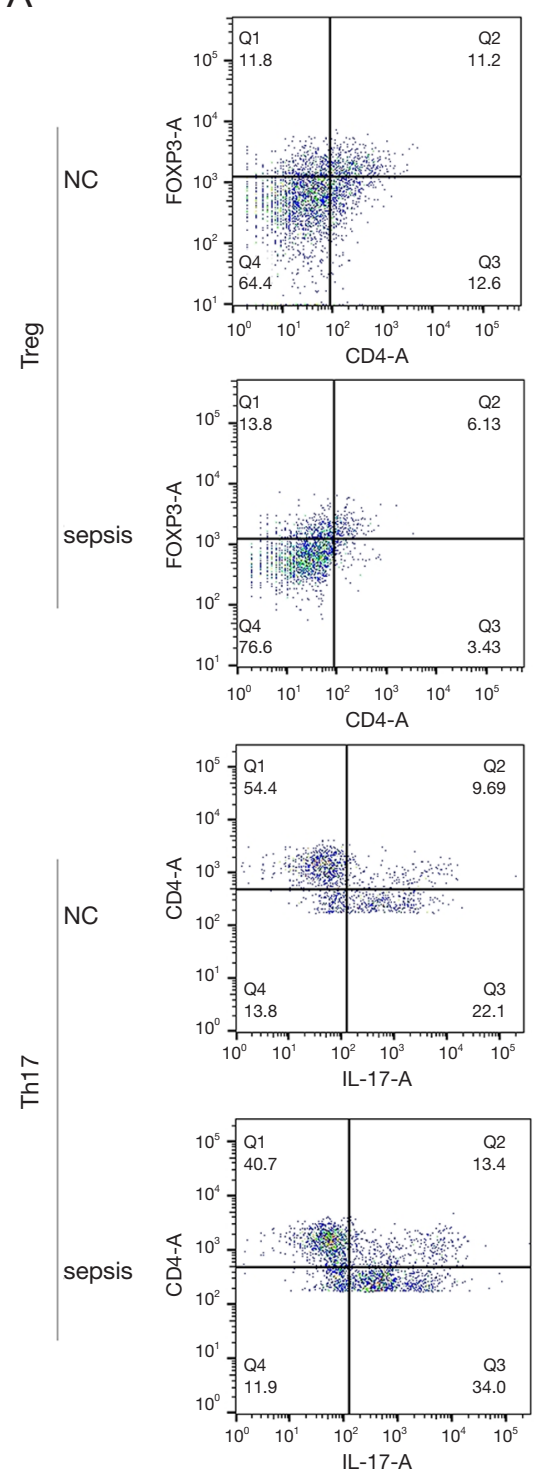

B

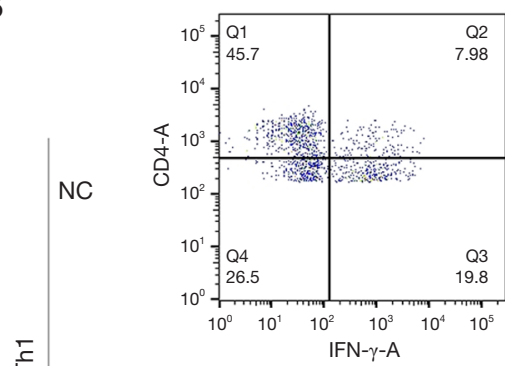

$\bar{F}$
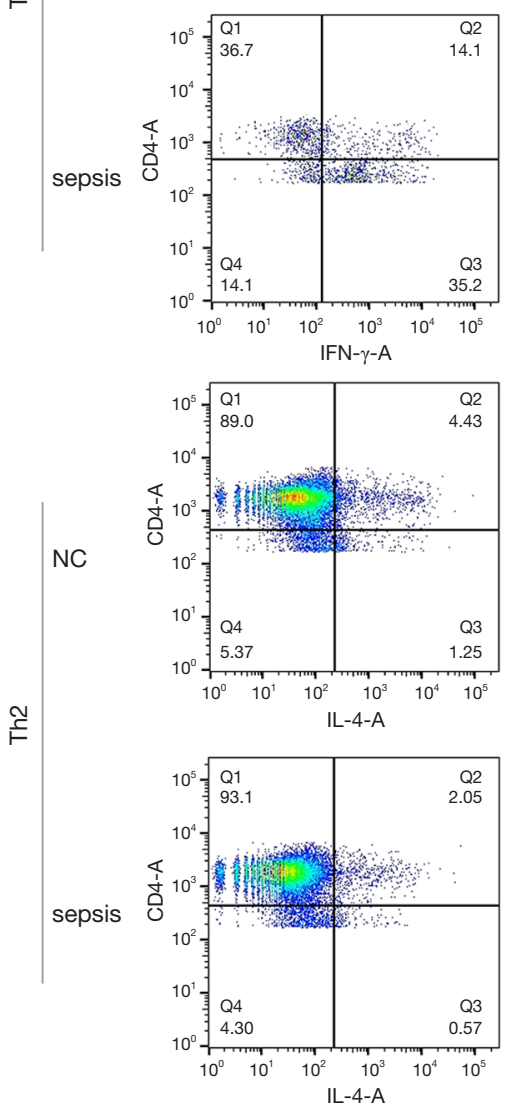

テั
C
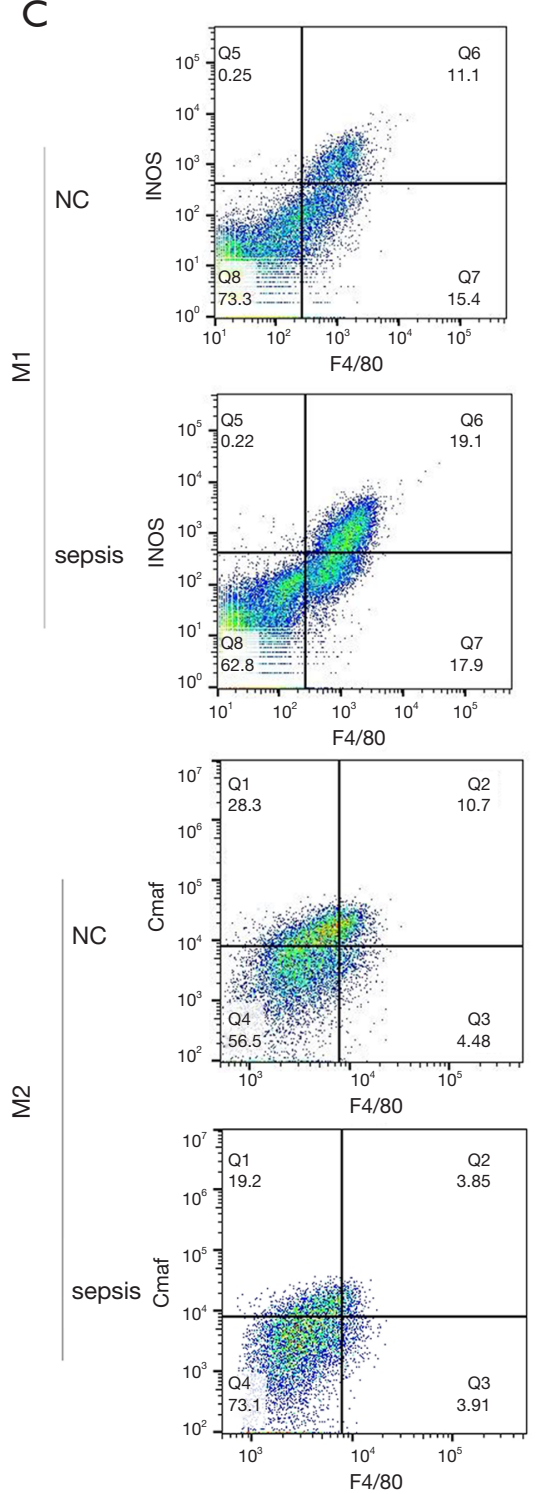

Figure 2 Treg/Th17, Th1/Th2, and M1/M2 cell ratios in sepsis patients with pneumonia-induced sepsis. (A) The numbers of Treg and Th17 cells in patients with pneumonia-induced sepsis and normal samples detected by flow cytometry; (B) the numbers of Th1 and Th2 cells in patients with pneumonia-induced sepsis and normal samples detected by flow cytometry; (C) the numbers of M1 and M2 cells in patients with pneumonia-induced sepsis and normal samples detected by flow cytometry.

Firstly, the higher expression levels of IL-6, TNF- $\alpha$, IL-1 $\beta$, IL-18 and LDH were observed in patients with pneumonia-induced sepsis when compared with the control group (Figure $3 A, B$ ). Secondly, TEM showed PBMCs with plasma-membrane rupture, cell lysis, and more pore formation in the patients compared with the control group, indicating the occurrence of pyroptosis (Figure 3C). These results further confirmed that there was a severe inflammatory response in the patients.

Thirdly, compared with the control group, the expression levels of HMGB1, RAGE, IL-17A, TRAF6 and NK- $\kappa \mathrm{B}$ were obviously higher in the patients, indicating the activation of the IL-17 signaling pathway (Figure $3 A, D$ ). Moreover, pyroptosis is regulated via a caspase-1-dependent or caspase-1-independent mechanism, both of which lead to the release of IL-1 $\beta$ and IL-18 (19). Besides, NK- $\kappa B$ 

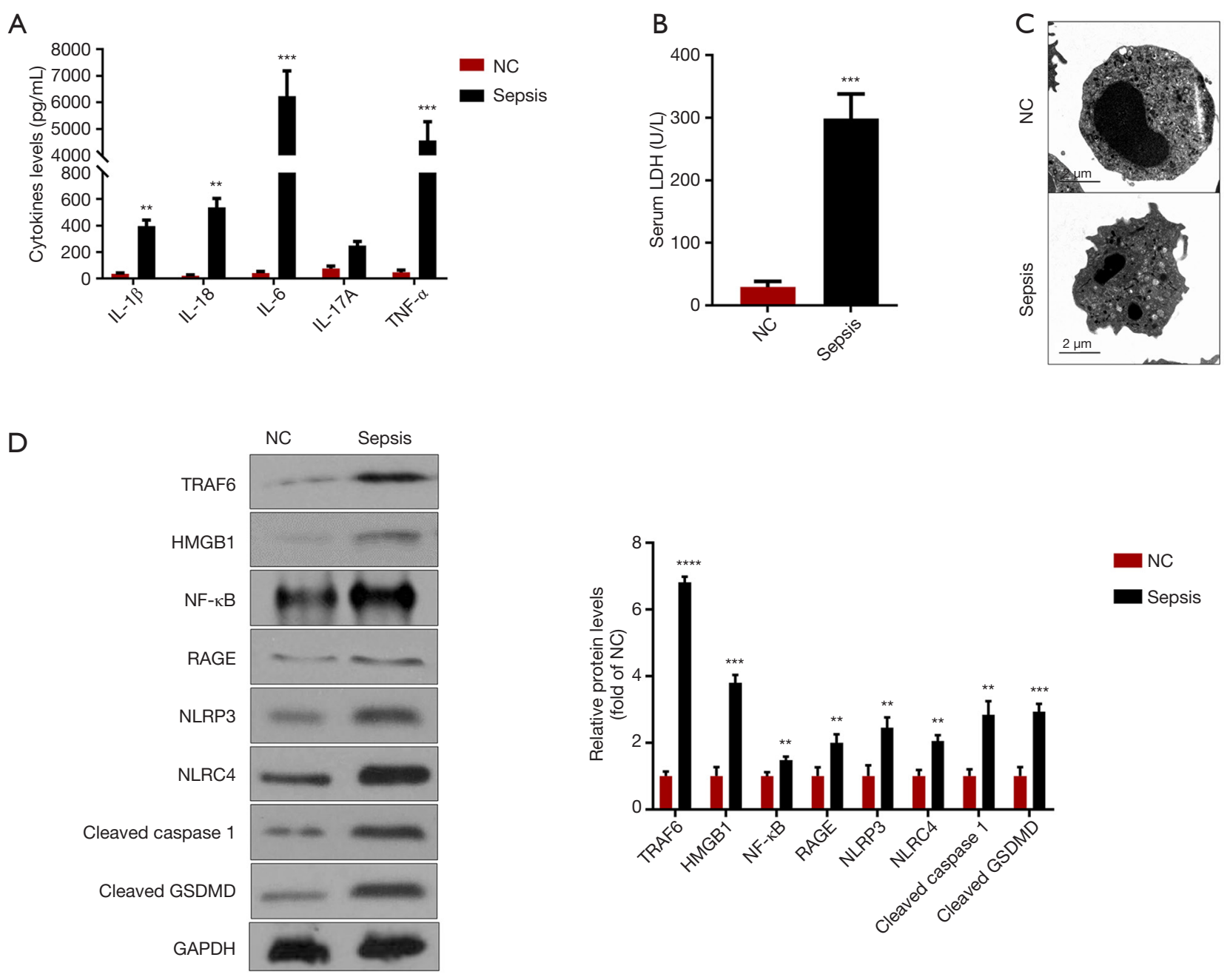

Figure 3 Inflammatory response and pyroptosis in patients with pneumonia-induced sepsis. (A) The expression levels of inflammatory cytokines, including IL-1 $\beta$, IL-18, IL-6, IL-17A, and TNF- $\alpha$, in patients with pneumonia-induced sepsis and normal blood samples by enzyme-linked immune-sorbent assays; (B) serum lactate dehydrogenase (LDH) level in patients with pneumonia-induced sepsis and normal blood samples by the commercial kit; (C) peripheral blood mononuclear cells (PBMCs) from peripheral blood in patients with pneumoniainduced sepsis and normal blood samples by transmission electron microscopy; (D) the protein molecules (HMGB1, RAGE, TRAF6 and NK-кB) in the IL-17 signaling pathway as well as pyroptosis-related proteins, including NLRP3, NLRC4, Cleaved Caspase1, and Cleaved GSDMD, in patients with pneumonia-induced sepsis and normal samples by western blotting. **, $\mathrm{P}<0.01,{ }^{* * *}, \mathrm{P}<0.001$ and ${ }^{* * * *}, \mathrm{P}<0.0001$ compared with NC group.

activation is critical for promoting caspase-1-dependent pyroptosis (18). Figure $3 D$ also indicated that the expression levels of the proteins (NLRP3, NLRC4, Cleaved caspase1, and Cleaved GSDMD) associated with caspase-1-dependent pyroptosis were up-regulated in the patients as compared to the control groups. Hence, we speculated that the activation of the IL-17 signaling pathway could promote the pyroptosis in patients with pneumonia-induced sepsis.

\section{Tb17/Treg, Th1/Tb2, and M1/M2 cell ratios in pneumonia-induced sepsis rat models}

To further validate the above findings, the Th17/ Treg, Th1/Th2, and M1/M2 cell ratios in pneumonia-induced sepsis rat models were also determined by flow cytometry. The gating strategy of flow cytometry has been listed in Figures $54, S 5$. Compared with the control rats, Figure $4 \mathrm{~A}$ indicates that the percentages of Treg cells $\left(\mathrm{CD}^{+}, \mathrm{FOXP}^{+}\right)$ 
A

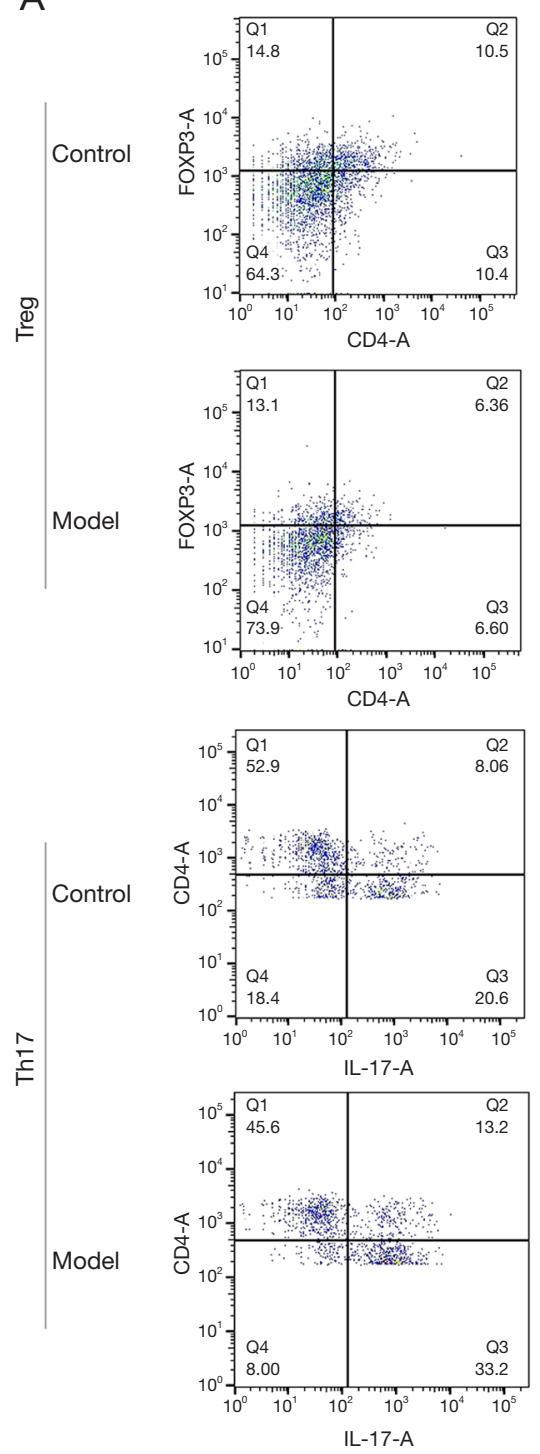

B
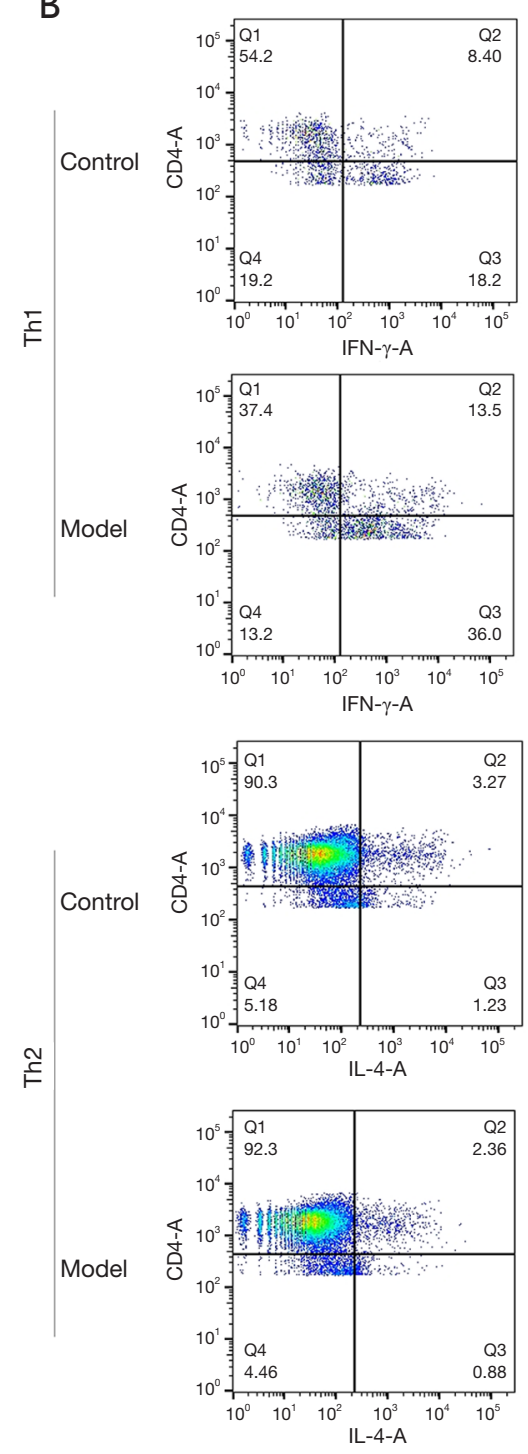
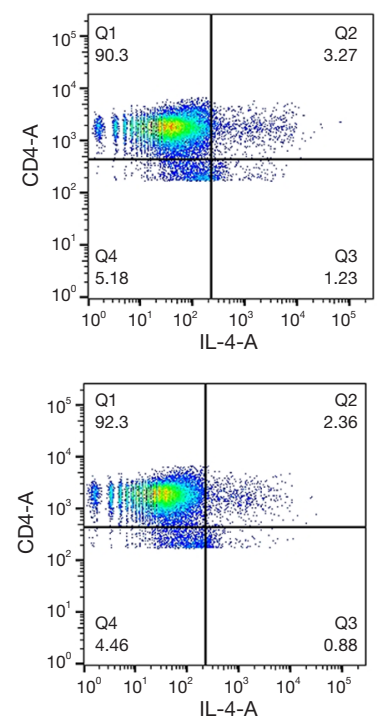

C
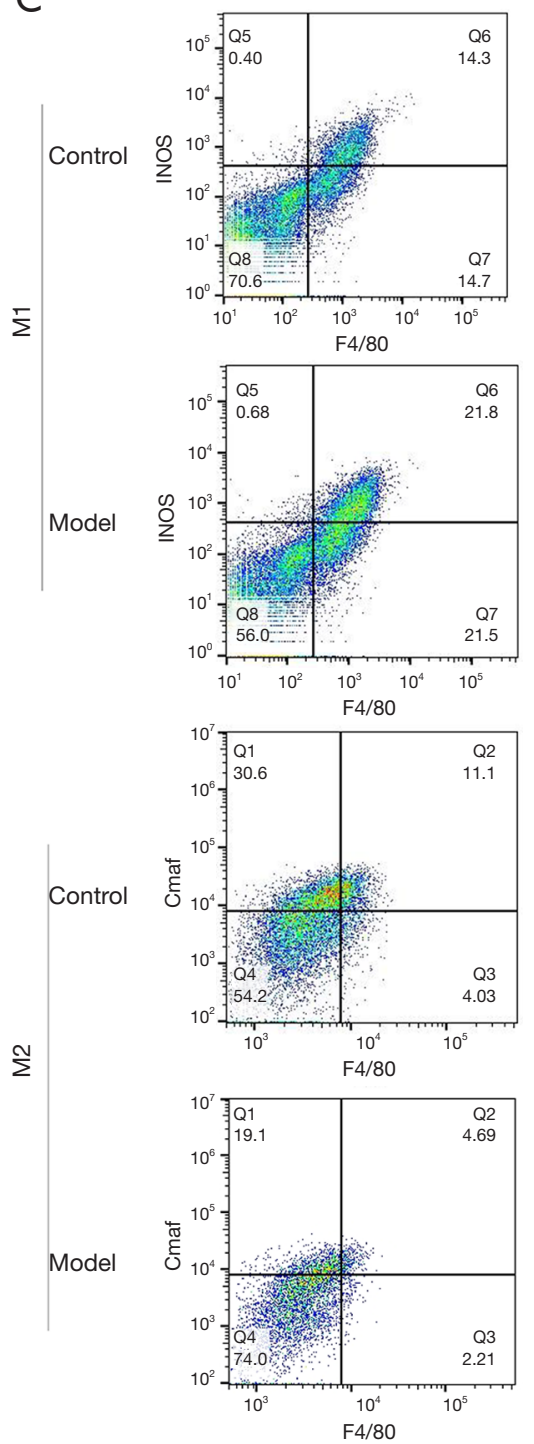

Figure 4 Treg/Th17, Th1/Th2, and M1/M2 cell ratios in pneumonia-induced sepsis rat models. (A) The numbers of Treg and Th17 cells in pneumonia-induced sepsis rats and normal rats detected by flow cytometry; (B) the numbers of Th1 and Th2 cells in pneumonia-induced sepsis rats and normal rats detected by flow cytometry; (C) the numbers of M1 and M2 cells in pneumonia-induced sepsis rats and normal rats detected by flow cytometry.

in pneumonia-induced sepsis rats were significantly downregulated $(6.36 \%$ vs. $10.5 \%)$, while the percentages of Th17 cells $\left(\mathrm{CD} 4^{+}, \mathrm{IL}-17^{+}\right)$were obviously up-regulated $(13.2 \%$ vs. $8.06 \%)$.

Figure $4 B$ shows that the percentages of Th1 cells $\left(\mathrm{CD}^{+}\right.$, IFN $\gamma^{+}$) had a relatively high level in pneumonia-induced sepsis rats as compared to the control rats $(13.5 \%$ vs. $8.4 \%)$, whereas the percentages of Th2 cells $\left(\mathrm{CD} 4^{+}, \mathrm{IL}-4^{+}\right)$in pneumonia-induced sepsis rats showed a relatively low level

\section{(2.36\% vs. $3.27 \%)$.}

In addition, Figure $4 C$ indicates that the percentages of $\mathrm{M} 1$ cells $\left(\mathrm{F} 4 / 80^{+}, \mathrm{iNOS}^{+}\right)$in pneumonia-induced sepsis rats were higher than that in the control rats $(21.8 \% v s .14 .3 \%)$. In contrast, the percentages of $\mathrm{M} 2$ cells $\left(\mathrm{F} 4 / 80^{+}, \mathrm{Cmaf}^{+}\right)$in pneumonia-induced sepsis rats were lower than that in the control rats (4.69\% vs. $11.1 \%)$.

Therefore, there was a high value of Th17/Treg, Th1/ Th2 and M1/M2 radios in pneumonia-induced sepsis rats 

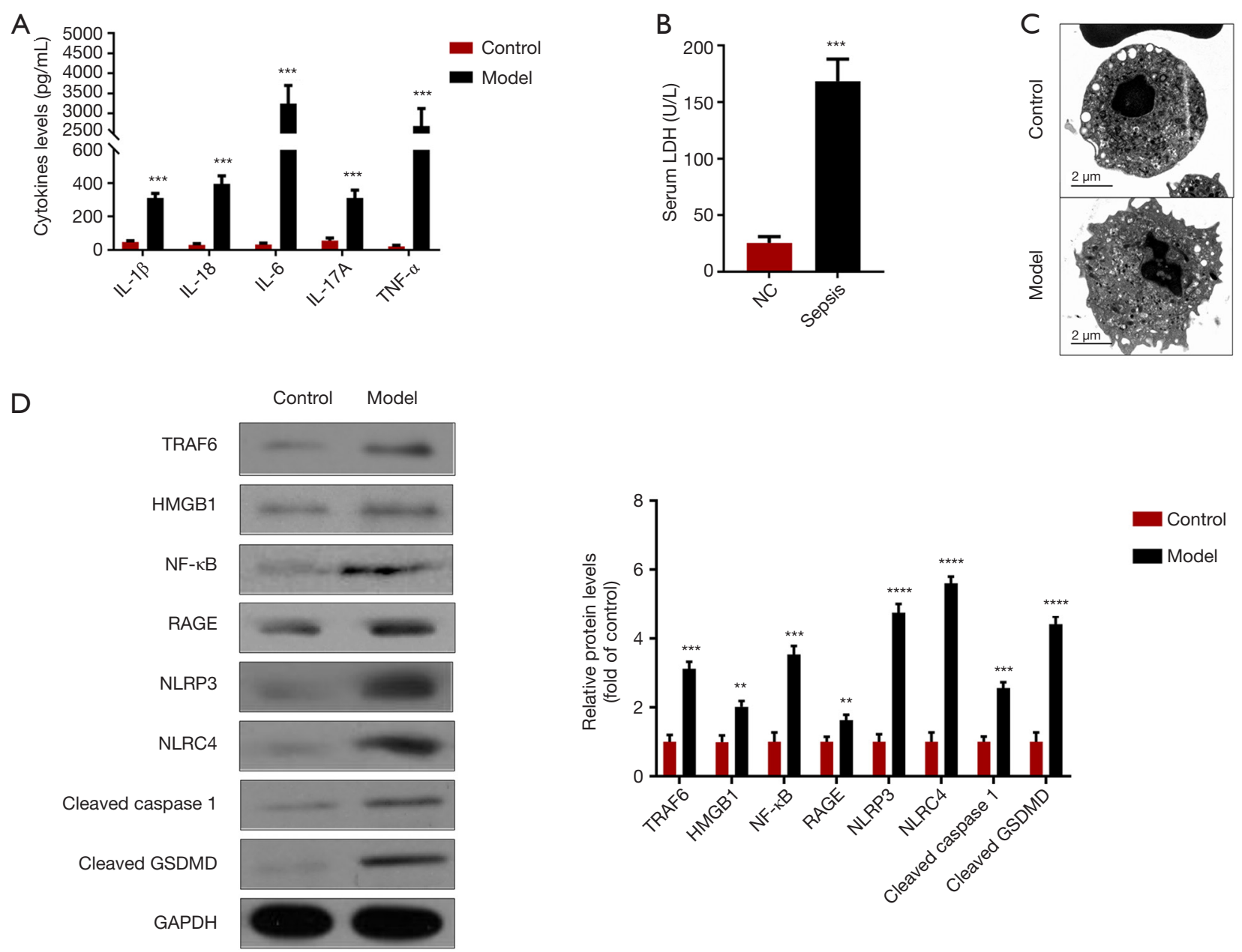

Figure 5 Inflammatory response and pyroptosis in pneumonia-induced sepsis rat models. (A) The expression levels of inflammatory cytokines, including IL-1 $\beta$, IL-18, IL-6, IL-17A, and TNF- $\alpha$, in pneumonia-induced sepsis rats and normal rats by enzyme-linked immunesorbent assays; (B) serum lactate dehydrogenase level (LDH) in pneumonia-induced sepsis rats and normal rats by the commercial kit; (C) peripheral blood mononuclear cells (PBMCs) in pneumonia-induced sepsis rats and normal rats by transmission electron microscopy;

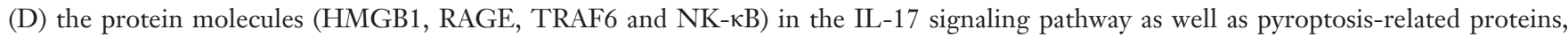
including NLRP3, NLRC4, Cleaved Caspase1, and Cleaved GSDMD, in pneumonia-induced sepsis rats and normal rats by western blotting. ${ }^{* *}, \mathrm{P}<0.01$, ***, $\mathrm{P}<0.001$, and ${ }^{* * *}, \mathrm{P}<0.0001$ compared with Control group

compared with the control rats. Additionally, there was a higher frequency of IL-17, IFN $\gamma$, and iNOS production and a lower frequency of FOXP3, IL-4, and Cmaf production. Hence, the radio imbalance also indicated that there was a severe inflammatory response in pneumonia-induced sepsis rats, and the model of pneumonia-induced sepsis rats had been successfully established.

\section{Inflammatory response and pyroptosis in pneumonia- induced sepsis rat models}

Similar to the results of clinical samples, the expression levels of IL-1 $\beta$, IL-18, IL-6, IL-17A, TNF- $\alpha$, and LDH were significantly increased in pneumonia-induced sepsis rats when compared with normal rats (Figure $5 A, B, \mathrm{P}<0.05$ ). 
Moreover, TEM also found PBMCs with plasma-membrane rupture, cell lysis, and more pore formation in pneumoniainduced sepsis rats compared with normal rats, indicating the occurrence of pyroptosis (Figure 5C). Western blotting also showed that the protein expression levels of the key molecules (HMGB1, RAGE, TRAF6 and NK- $\kappa$ B) in the IL-17 signaling pathway, as well as pyroptosis-related proteins, including NLRP3, NLRC4, Cleaved Caspase1, and Cleaved GSDMD, were all prominently up-regulated in pneumonia-induced sepsis rats compared with normal rats (Figure $5 D, \mathrm{P}<0.05$ ). Therefore, these findings further confirmed that the activation of the IL-17 signaling pathway could promote pyroptosis in pneumonia-derived sepsis and cause a severe inflammatory response.

\section{Discussion}

The current study found that IL-17 signaling pathway was significantly related to the development of pneumoniainduced sepsis by bioinformatics analysis. Compared with healthy groups, the higher of Th17/Treg, Th1/Th2 and M1/M2 cell radios in patients and sepsis rat model indicated that pneumonia-induced sepsis caused a severe inflammatory response. This result was further confirmed by the higher levels of pro-inflammatory factors (IL-1 $\beta$, IL-18, IL-6, IL-17A, and TNF- $\alpha$ ) and LDH, as well as pyroptosis occurrence in pneumonia-induced sepsis. In addition, the up-regulation of the upstream and downstream molecules (HMGB1, RAGE, IL-17A, TRAF6 and NK-кB) in the IL-17 signaling pathway suggested the IL-17 signaling was activated. Moreover, the release of IL- $1 \beta$ and IL-18 and the levels of the molecules (NLRP3, NLRC4, Cleaved caspase-1, and Cleaved GSDMD) associated with caspase-1-dependent pyroptosis were up-regulated in pneumonia-induced sepsis. As NK- $\kappa \mathrm{B}$ activation can promote the development of caspase-1-dependent pyroptosis, we speculated that the activation of the IL-17 signaling pathway could promote pyroptosis in pneumoniainduced sepsis.

It is well known that innate immune cells such as monocytes and macrophages can be activated by pathogenassociated molecular patterns molecules, thereby activating inflammatory cells and increasing the levels of proinflammatory cytokines (20). This study found that higher Th17/Treg, Th1/Th2 and M1/M2 cell ratios in pneumoniainduced sepsis. $\mathrm{CD}^{+} \mathrm{T}$ cell subsets consist of Th1, Th2, Treg and Th17 cells, which participate in the advancement of immunoinflammatory diseases $(21,22)$. Treg cells, mainly express Foxp3, can release anti-inflammatory cytokine IL10 and exhibit immunosuppressive effect (23). Th17 cells can induce autoimmune inflammatory reactions by secreting IL-1 $\beta$, IL-18, IL-6, IL-17A, and TNF- $\alpha$ (23). The relative balance of Th17 and Treg cells is considered as a critical indicator to induce pro- or anti-inflammatory reactions and maintain immune homeostasis (23). It has been shown that Th17 cells play important roles in several lung diseases, such as chronic obstructive pulmonary disease (24), lung cancer (25), tuberculosis (26), and asthma (27), and the number of Th17 cells is obviously increased in sepsis (28). Additionally, T-helper 1 (Th1) and Th2 cells, two classical subsets of $\mathrm{CD}^{+} \mathrm{T}$ cells, are critical for immune-related disorder (29). Previous study has found the increased proinflammatory Th1 cell and decreased anti-inflammatory Th2 cells according to the elevated level of IFN $\gamma$ and the reduced level of IL-4 in sepsis (30). Furthermore, macrophages can differentiate into the classically activated phenotype (M1) and the alternatively activated phenotype (M2), responsible for immune-inflammatory diseases (31). M1 cells have pro-inflammatory effect, characterized by upregulated CD11c, CD86, and iNOS; conversely, M2 cells have anti-inflammatory reactions, characterized by release of CD163, CD206, arginase 1, and Cmaf (32). M1/M2 polarization has been reported to be associated with various pathological conditions such as infection and inflammation $(33,34)$. The increase M1 cells and decrease M2 cells were found in sepsis mouse model, which inferred from the higher release of cytokines (IL- 6 and TNF- $\alpha$ ) from M1 cells and the lower release of cytokine (IL-10) from M2 cells (35). Therefore, the imbalance of Th17/Treg, Th1/Th2, and M1/ M2 in the present study could promote the occurrence and development of sepsis, and their higher cell ratios indicated that there was a severe inflammatory response caused by pneumonia-induced sepsis. Furthermore, IL-6, TNF- $\alpha$, IL$17 \mathrm{~A}, \mathrm{IL}-1 \beta$, and IL-18 are known as key pro-inflammatory factors (36), and serum LDH and pyroptosis are regarded as important indicators of inflammation $(10,37)$. In this study, the higher levels of IL-6, TNF- $\alpha$, IL-17A, IL-1 $\beta$, IL-1, and LDH, as well as pyroptosis occurrence further confirmed that there was a severe inflammatory response in pneumonia-induced sepsis.

Pyroptosis is a proinflammatory form of regulated cell death that relies on cytosolic inflammasome activation (10). Besides, pyroptosis can be stimulated by plenty of pathological stimuli, mainly including microbial infection, heart attack, cancer, or stroke (38). Accumulating evidence suggests that pyroptosis is regulated by a caspase-1- 
dependent or caspase-1-independent mechanism, both of which can lead to the release of IL-1 $\beta$ and IL-18 (19). In caspase-1-dependent pyroptosis, caspase- 1 is activated by inflammasome-initiating sensors (e.g., NLRP3, NLRC4) on recognition of danger- or pathogen-associated molecular patterns, which is considered as canonical inflammasome activation (19). NLRP3 inflammasome is one of the known inflammasome complexes, and it can be activated and then induce caspase- 1 activation during pyroptosis $(39,40)$. Similarly, NLRC4 inflammasome is another inflammasome complex regardless of the Nlrp3 inflammasome, which is also involved in the inflammation response to bacterial infection, thereby contributing to pyroptosis dependent on caspase-1 activation (41). Importantly, GSDMD protein is cleaved by the inflammatory caspase to trigger pyroptosis, which results in pore formation in the plasma membrane and lytic cell death (42). In the present study, IL-1 $\beta$, IL-18, NLRP3, NLRC4, cleaved GSDMD and cleaved caspase-1 showed a relatively high level in pneumonia-induced sepsis compared with the control groups, and thus pyroptosis had largely appeared in pneumonia-induced sepsis.

The upstream and downstream molecules in the IL-17 signaling pathway mainly include HMGB1, RAGE, IL17A, TRAF6 and NK-кB $(16,17)$. HMGB1 (High-mobility group box 1 protein), an evolutionarily conserved and chromatin-binding protein that is released by inflammatory cells or necrotic cells, can bind to multiple receptors such as RAGE (advanced glycation end products) to trigger IL-17A production $(16,43)$. IL-17A interacts with the association of the IL-17-binding receptor with Act1 (44). Act1 rapidly recruits and ubiquitinates TRAF6 (TNF-receptor associated factor 6 ), and then triggers $\mathrm{NF}-\mathrm{\kappa B}$ activation $(17,45)$. Moreover, NF- $\kappa \mathrm{B}$ can bind to TLR4 and NLRP3 promoter region and elevate GSDMD transcription, thereby promoting pyroptosis (18). In the present study, the experimental results revealed the high expression of key molecules (HMGB1, RAGE, IL-17A, TRAF6 and NK$\kappa \mathrm{B})$ of the IL-17 signaling pathway in pneumonia-induced sepsis. Therefore, we speculated that the activation of the IL-17 signaling pathway could promote pyroptosis in pneumonia-induced sepsis.

\section{Conclusions}

In summary, there was a severe inflammatory response in pneumonia-induced sepsis, and the activation of the IL-17 signaling pathway could promote pyroptosis. These results can provide a new insight for understanding the molecular mechanism of the inflammatory response in pneumoniainduced sepsis. Of course, the present work is a preliminary study and the roles of the IL-17 signaling pathway on pyroptosis in pneumonia-induced sepsis need to further validate by many basic biological experiments, animal experiments and clinical tests.

\section{Acknowledgments}

Funding: None.

\section{Footnote}

Data Sharing Statement: Available at http://dx.doi. org/10.21037/atm-19-1739

Conflicts of Interest: All authors have completed the ICMJE uniform disclosure form (available at http://dx.doi. org/10.21037/atm-19-1739). The authors have no conflicts of interest to declare.

Ethical Statement: The authors are accountable for all aspects of the work in ensuring that questions related to the accuracy or integrity of any part of the work are appropriately investigated and resolved. This study obtained ethical approval from the Ethics Committee of The First Affiliated Hospital, China Medical University (Approval Number: AF-SOP-07-1).

Open Access Statement: This is an Open Access article distributed in accordance with the Creative Commons Attribution-NonCommercial-NoDerivs 4.0 International License (CC BY-NC-ND 4.0), which permits the noncommercial replication and distribution of the article with the strict proviso that no changes or edits are made and the original work is properly cited (including links to both the formal publication through the relevant DOI and the license). See: https://creativecommons.org/licenses/by-nc-nd/4.0/.

\section{References}

1. Cohen J, Vincent JL, Adhikari NK, et al. Sepsis: a roadmap for future research. Lancet Infect Dis 2015;15:581-614.

2. Reinhart K, Daniels R, Kissoon N, et al. Recognizing Sepsis as a Global Health Priority - A WHO Resolution. N Engl J Med 2017;377:414-7.

3. Hoser GA, Skirecki T, Zlotorowicz M, et al. Absolute counts of peripheral blood leukocyte subpopulations in 
intraabdominal sepsis and pneumonia-derived sepsis: a pilot study. Folia Histochem Cytobiol 2012;50:420-6.

4. Ljungström LR, Jacobsson G, Claesson BEB, et al. Respiratory viral infections are underdiagnosed in patients with suspected sepsis. Eur J Clin Microbiol Infect Dis 2017;36:1767-76.

5. Pereira JM, Paiva JA, Rello J. Severe sepsis in communityacquired pneumonia - Early recognition and treatment. Eur J Intern Med 2012;23:412-9.

6. Rhodes A, Evans LE, Alhazzani W, et al. Surviving Sepsis Campaign: International Guidelines for Management of Sepsis and Septic Shock. Crit Care Med 2017;45:486.

7. Seymour CW, Gesten F, Prescott HC, et al. Time to Treatment and Mortality during Mandated Emergency Care for Sepsis. New Engl J Med 2017;376:2235-44.

8. Shi J, Gao W, Shao F. Pyroptosis: Gasdermin-Mediated Programmed Necrotic Cell Death. Trends Biochem Sci 2017;42:245-54.

9. Bergsbaken T, Fink SL, Cookson BT. Pyroptosis: host cell death and inflammation. Nat Rev Microbiol 2009;7:99-109.

10. Vande Walle L, Lamkanfi M. Pyroptosis. Curr Biol 2016;26:R568-72.

11. Aglietti RA, Dueber EC. Recent Insights into the Molecular Mechanisms Underlying Pyroptosis and Gasdermin Family Functions. Trends Immunol 2017;38:261-71.

12. Gao YL, Zhai JH, Chai YF. Recent Advances in the Molecular Mechanisms Underlying Pyroptosis in Sepsis. Mediators Inflamm 2018;2018:5823823.

13. Pawitan Y, Michiels S, Koscielny S, et al. False discovery rate, sensitivity and sample size for microarray studies. Bioinformatics 2005;21:3017-24.

14. Knaus WA, Draper EA, Wagner DP, et al. APACHE II: a severity of disease classification system. Crit Care Med 1985;13:818-29.

15. Vincent JL, de Mendonca A, Cantraine F, et al. Use of the SOFA score to assess the incidence of organ dysfunction/ failure in intensive care units: results of a multicenter, prospective study. Working group on "sepsis-related problems" of the European Society of Intensive Care Medicine. Crit Care Med 1998;26:1793-800.

16. Hu X, Zhang K, Chen Z, et al. The HMGB1IL17A axis contributes to hypoxia/reoxygenation injury via regulation of cardiomyocyte apoptosis and autophagy. Mol Med Rep 2018;17:336-41.

17. McGeachy MJ, Cua DJ, Gaffen SL. The IL-17 Family of Cytokines in Health and Disease. Immunity
2019;50:892-906.

18. Liu Z, Gan L, Xu Y, et al. Melatonin alleviates inflammasome-induced pyroptosis through inhibiting NFkappaB/GSDMD signal in mice adipose tissue. J Pineal Res 2017;63. doi: 10.1111/jpi.12414.

19. Man SM, Karki R, Kanneganti TD. Molecular mechanisms and functions of pyroptosis, inflammatory caspases and inflammasomes in infectious diseases. Immunol Rev 2017;277:61-75.

20. Matsuda A, Jacob A, Wu R, et al. Novel Therapeutic Targets for Sepsis: Regulation of Exaggerated Inflammatory Responses. J Nippon Med Sch 2012;79:4-18.

21. Noack M, Miossec P. Th17 and regulatory T cell balance in autoimmune and inflammatory diseases. Autoimmun Rev 2014;13:668-77.

22. Moss RB, Moll T, El-Kalay M, et al. Th1/Th2 cells in inflammatory disease states: Therapeutic implications. Expert Opin Biol Ther 2004;4:1887-96.

23. Lee YK, Mukasa R, Hatton RD, et al. Developmental plasticity of Th17 and Treg cells. Curr Opin Immunol 2009;21:274-80.

24. Wang H, Ying H, Wang S, et al. Imbalance of peripheral blood Th17 and Treg responses in patients with chronic obstructive pulmonary disease. Clin Respir J 2015;9:330-41.

25. Wu H, Wang K, Li G, et al. Effects of transcutaneous acupoint electrical stimulation on the imbalance of Th1, Th2, Th17 and Treg cells following thoracotomy of patients with lung cancer. Exp Ther Med 2016;11:495-502.

26. Kononova TE, Urazova OI, Novitskii VV, et al. Functional Activity of Th-17 Lymphocytes in Pulmonary Tuberculosis. Bull Exp Biol Med 2014;156:743-5.

27. Newcomb DC, Peebles RS. Th17-mediated inflammation in asthma. Curr Opin Immunol 2013;25:755-60.

28. Rendon JL, Choudhry MA. Th17 cells: critical mediators of host responses to burn injury and sepsis. J Leukocyte Biol 2012;92:529-38.

29. Jankovic D, Feng CG. CD4(+) T Cell Differentiation in Infection: Amendments to the Th1/Th2 Axiom. Front Immunol 2015;6:198.

30. Kasten KR, Tschöp J, Adediran SG, et al. T cells are potent early mediators of the host response to sepsis. Shock 2010;34:327-36.

31. Gordon S, Martinez FO. Alternative Activation of Macrophages: Mechanism and Functions. Immunity 2010;32:593-604. 
32. Labonte AC, Tosello-Trampont AC, Hahn YS. The Role of Macrophage Polarization in Infectious and Inflammatory Diseases. Mol Cells 2014;37:275-85.

33. Komohara Y, Fujiwara Y, Ohnishi K, et al. Contribution of Macrophage Polarization to Metabolic Diseases. J Atheroscler Thromb 2016;23:10-7.

34. Atri C, Guerfali FZ, Laouini D. Role of Human Macrophage Polarization in Inflammation during Infectious Diseases. Int J Mol Sci 2018;19:1801.

35. Liu YC, Feng-Hua Y, Yan-Fen C, et al. Xuebijing Injection Promotes M2 Polarization of Macrophages and Improves Survival Rate in Septic Mice. Evid Based Complement Alternat Med 2015;2015:352642.

36. Wojdasiewicz P, Poniatowski LA, Szukiewicz D. The role of inflammatory and anti-inflammatory cytokines in the pathogenesis of osteoarthritis. Mediators Inflamm 2014;2014:561459.

37. Jung SH, Yang DH, Ahn JS, et al. Serum lactate dehydrogenase with a systemic inflammation score is useful for predicting response and survival in patients with newly diagnosed diffuse large B-cell lymphoma. Acta Haematol 2015;133:10-7.

38. Deutschman CS, Tracey KJ. Sepsis: Current Dogma and New Perspectives. Immunity 2014;40:463-75.

Cite this article as: Li LL, Dai B, Sun YH, Zhang TT. The activation of IL-17 signaling pathway promotes pyroptosis in pneumonia-induced sepsis. Ann Transl Med 2020;8(11):674. doi: $10.21037 /$ atm-19-1739
39. Guo H, Callaway JB, Ting JP. Inflammasomes: mechanism of action, role in disease, and therapeutics. Nat Med 2015;21:677-87.

40. Croker BA, O'Donnell JA, Gerlic M. Pyroptotic death storms and cytopenia. Curr Opin Immunol 2014;26:128-37.

41. Cerqueira DM, Pereira MSF, Silva ALN, et al. Caspase-1 but Not Caspase-11 Is Required for NLRC4-Mediated Pyroptosis and Restriction of Infection by Flagellated Legionella Species in Mouse Macrophages and In Vivo. J Immunol 2015;195:2303-11.

42. Shi J, Zhao Y, Wang K, et al. Cleavage of GSDMD by inflammatory caspases determines pyroptotic cell death. Nature 2015;526:660-5.

43. Yan B, Chen F, Xu L, et al. HMGB1-TLR4-IL23IL17A axis promotes paraquat-induced acute lung injury by mediating neutrophil infiltration in mice. Sci Rep 2017;7:597.

44. Monin L, Gaffen SL. Interleukin 17 Family Cytokines: Signaling Mechanisms, Biological Activities, and Therapeutic Implications. Cold Spring Harb Perspect Biol 2018;10.

45. Amatya N, Garg AV, Gaffen SL. IL-17 Signaling: The Yin and the Yang. Trends Immunol 2017;38:310-22. 


\section{Supplementary}

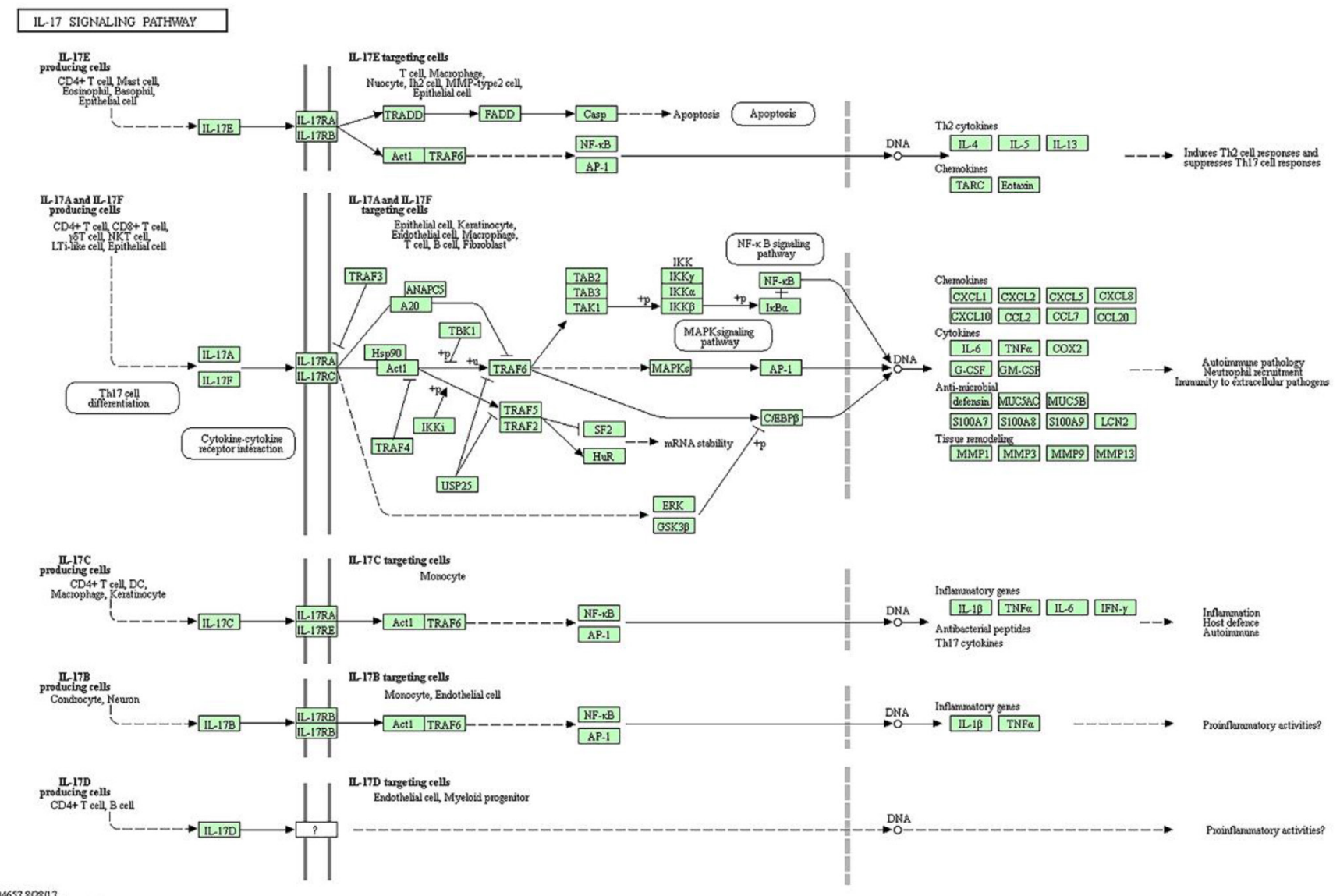

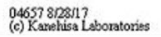

Figure S1 The graph of the IL-17 signaling pathway in KEGG database. 

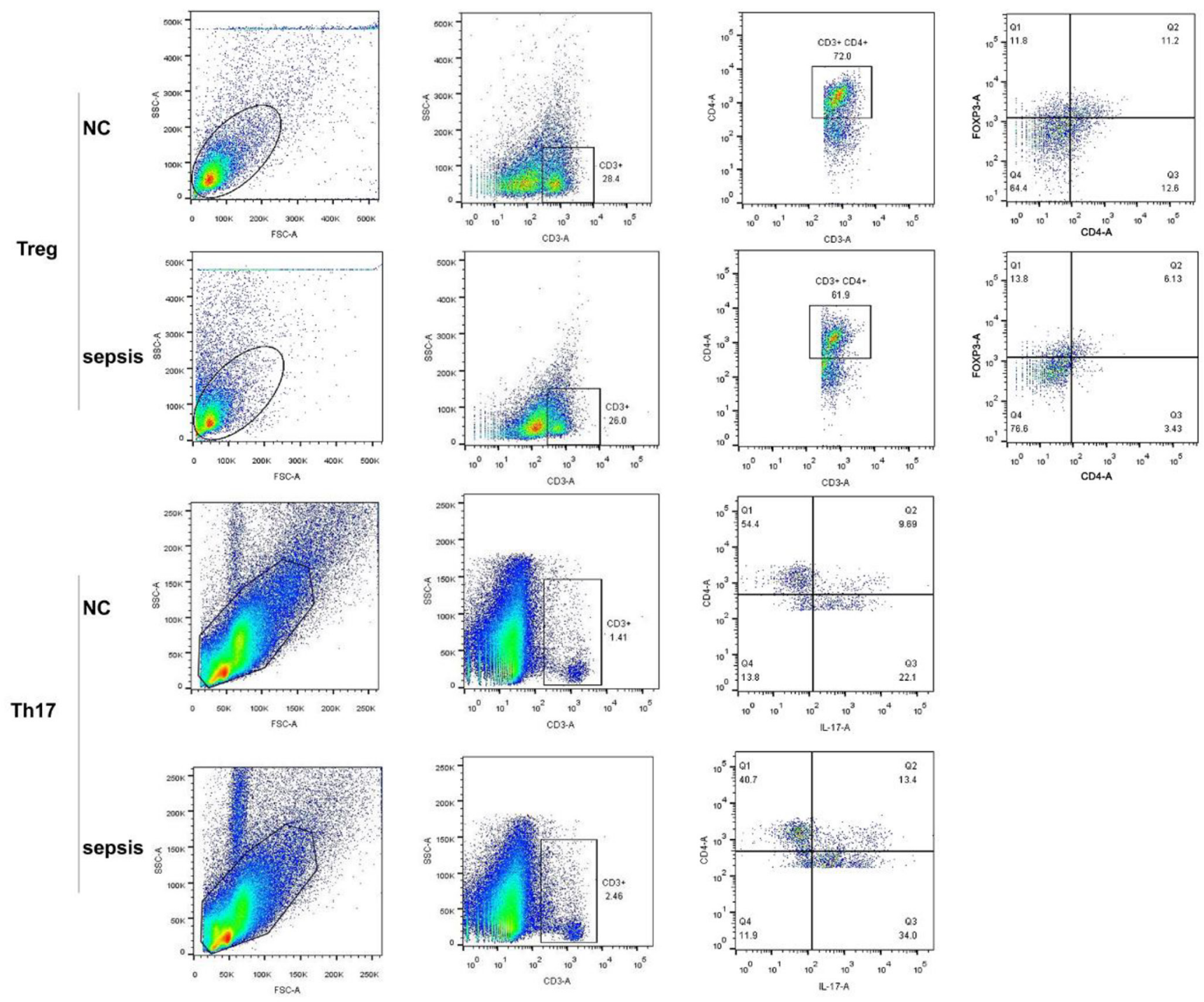

Figure S2 The gating strategy of flow cytometry for detecting Treg cells and Th17 cells from patients with pneumonia-induced sepsis. 

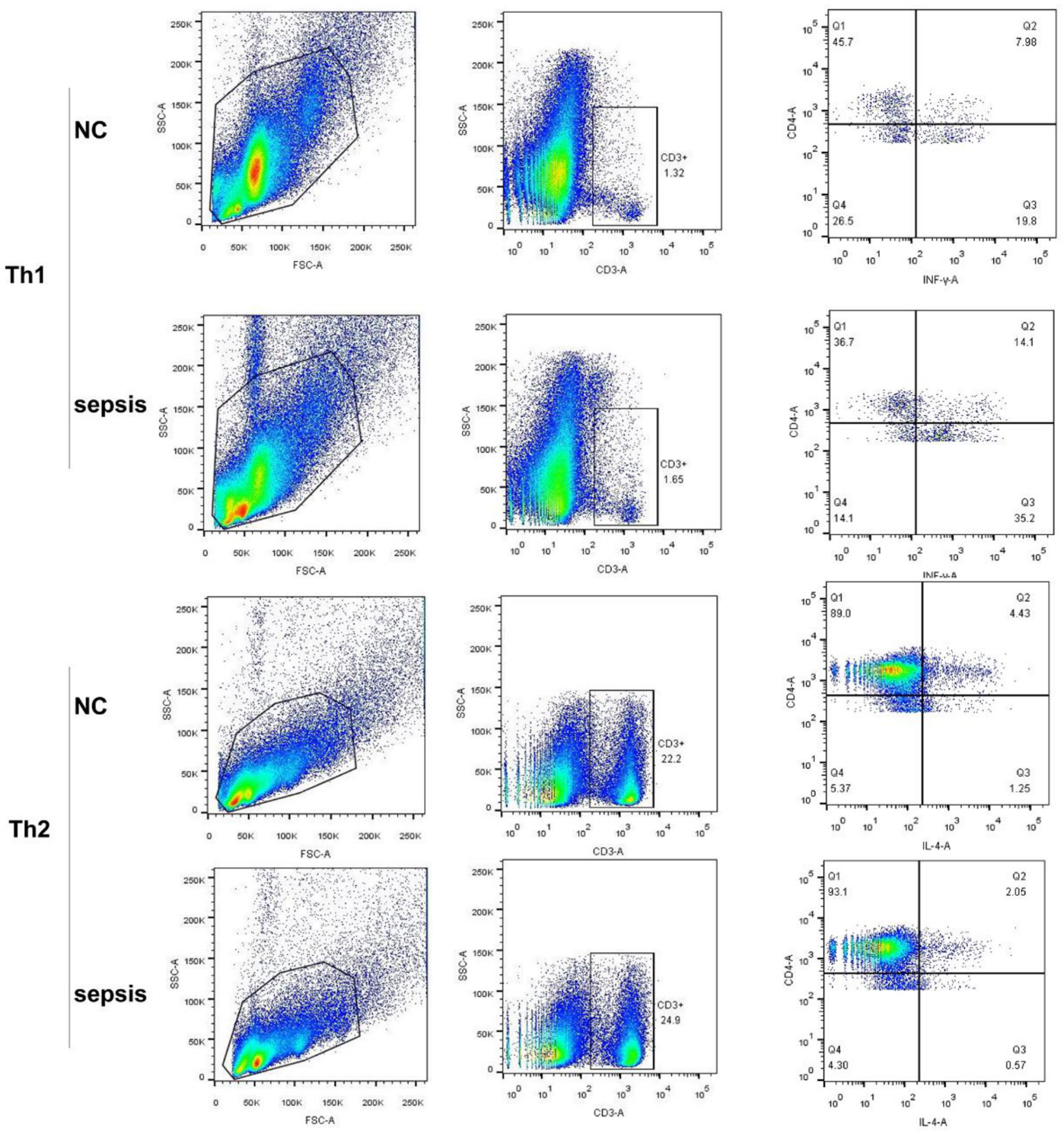

Figure S3 The gating strategy of flow cytometry for detecting Th1 cells and Th2 cells from patients with pneumonia-induced sepsis. 

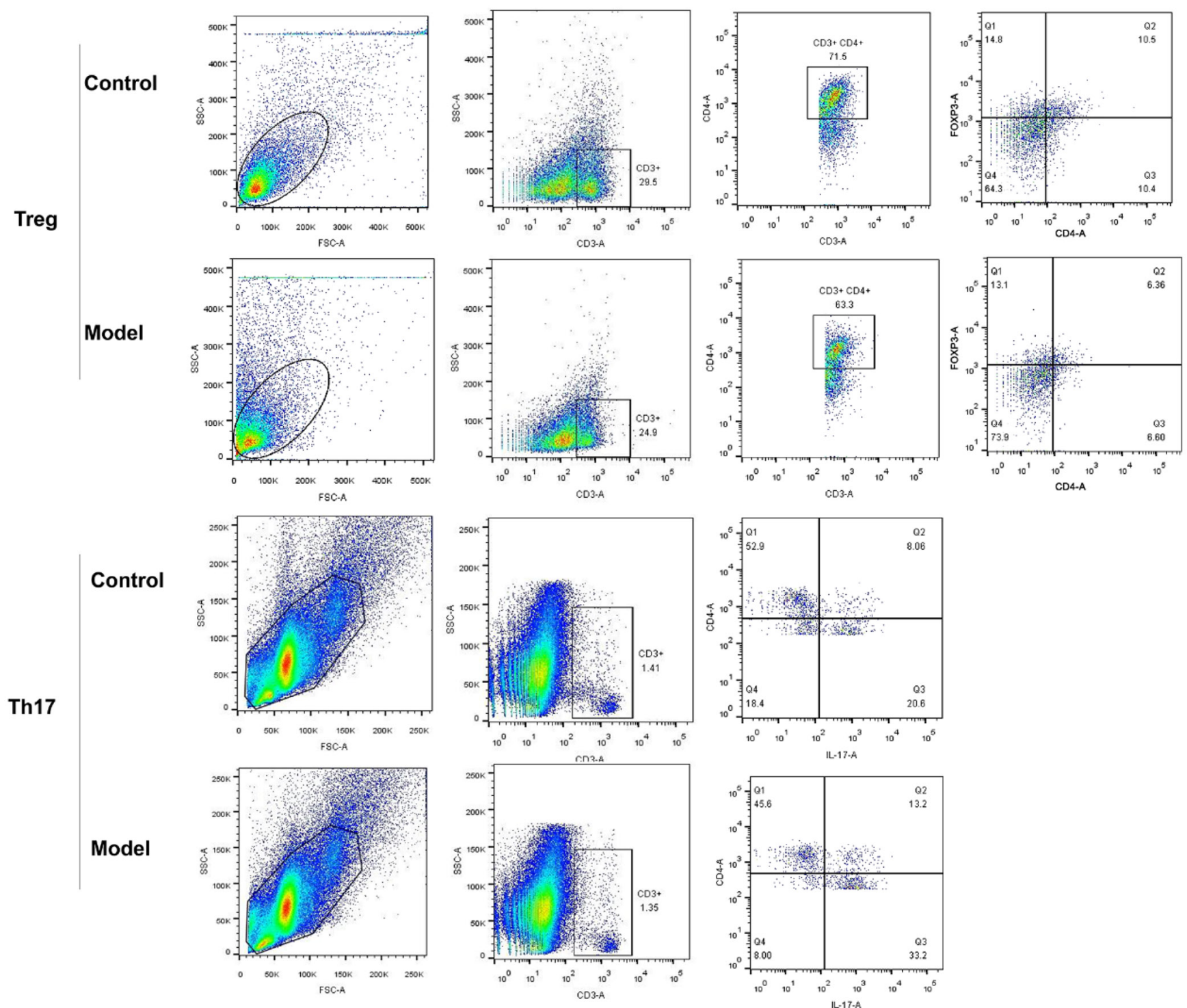

Figure S4 The gating strategy of flow cytometry for detecting Treg cells and Th17 cells from pneumonia-induced sepsis rat models. 

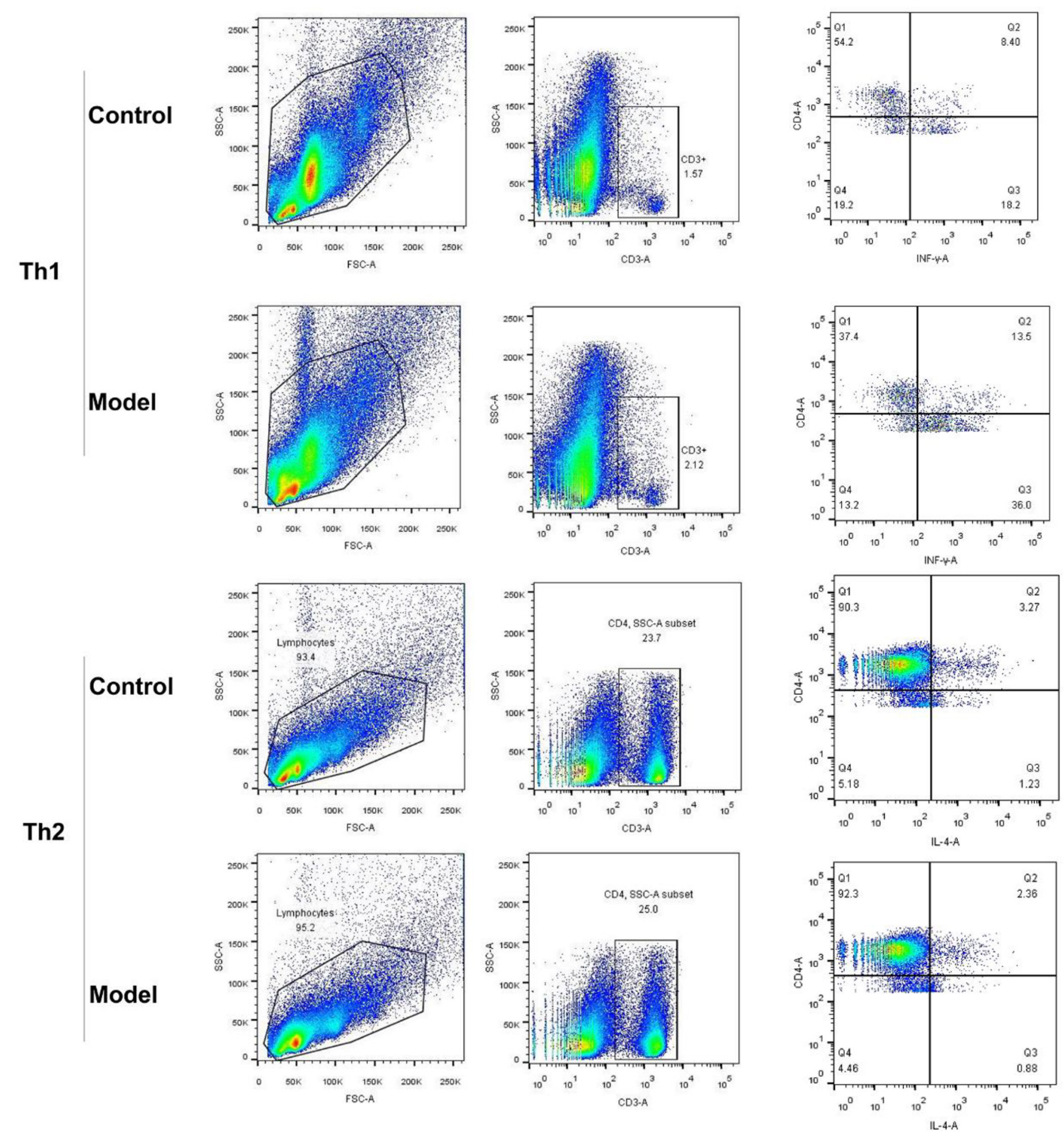

Figure S5 The gating strategy of flow cytometry for detecting Th1 cells and Th2 cells from pneumonia-induced sepsis rat models. 